\title{
Mortality Map
}

National Cancer Institute

\section{Source}

National Cancer Institute. Mortality Map. NCI Thesaurus. Code C16066.

A visual representation of the national cancer burden. These maps display cancer

mortality data by county and state economic regions across the country. They are color

coded to disting uish between regions with high, intermediate, and low rates of cancer mortality. 